\title{
PHENOLIC CONTENTS, ANTIOXIDANT PROPERTIES, AND SENSORY PROFILES OF WHEAT ROUND ROLLS SUPPLEMENTED WITH WHOLE GRAIN CEREALS
}

\author{
A. Mikulajováa* ${ }^{a *}$ Z. Kohajdováb, K. NÉmeth and E. Hybenováa \\ ${ }^{\mathrm{a}}$ Department of Nutrition and Food Assessment, Institute of Biochemistry, Nutrition and Health Protection, \\ ${ }^{b}$ Department of Food Science and Technology, Institute of Biotechnology and Food Science, Faculty of Chemical \\ and Food Technology, Slovak University of Technology in Bratislava, Radlinského 9, 81237 Bratislava. \\ Slovak Republic \\ ${ }^{c}$ Food Research Institute, Priemyselná 4, P. O. Box 25, 82475 Bratislava 26. Slovak Republic
}

(Received: 30 July, 2013; accepted: 16 November, 2013)

\begin{abstract}
Whole cereal flours (buckwheat, barley, and oat) and wheat bran were used to substitute $20 \%$ of white bakery wheat flour to prepare round rolls. Round roll quality was evaluated by determining total phenolic and total flavonoid contents, antioxidative capacity, the content of lipid hydroperoxides (primary oxidation products), and sensory profiling. Moreover, the stability of the phenolic compounds and antioxidant behaviour throughout processing was studied. Technological processing does not cause any significant loss of phenolics (less than 5\%). A significant increase in antioxidants and phenolics of the flour mixtures and final products were observed compared to those of white wheat round rolls (as control). Buckwheat and barley round roll crumbs contained the highest total phenolic and total flavonoid contents, and were the most effective in enhancing antioxidant activity, which increased 15 -fold and 8-fold, respectively, when compared to the control roll. The tested cereals effectively retarded formation of lipid hydroperoxides (from over $50 \%$ to control), which are undesirable from both a nutrition and storage/shelf life perspective. The results of sensory analyses showed that such bakery products are accepted by consumers with the exception of the product made with oat flour, where a reduction in the oat content would be preferable.
\end{abstract}

Keywords: cereals, phenolic compounds, flavonoids, stability, antioxidant activity, round roll

Cereal products, particularly bread, are important staple foods in many countries. Therefore, optimisation of the bread formula and enrichment of its bioactive ingredients is important to develop new bread types that combine beneficial health effects with favourable sensory properties.

Barley (Hordeum vulgare) and oat (Avena sativa) are excellent sources of $\beta$-glucans; in barley, these are mostly concentrated in the endosperm, while for oats they are found primarily in the subaleurone layer of the outer endosperm (Tiwari \& Cummins, 2012). $\beta$-glucans have been implicated in lowering plasma cholesterol, improving lipid metabolism, and reducing glycaemic index (IZydorczyK \& Dexter, 2008). Oat is a unique source of antioxidative avenanthramides and avenalumic acids, which are not reported in other grains (MiLler et al., 2000). Similarly, buckwheat (Fagopyrum spp.) is of interest for its content of flavonoids and rutin, which have many pharmacological effects (KREFT et al., 2002). The fact that buckwheat is gluten-free, suggests its application in diet therapy of subjects with celiac disease or gluten allergies. In comparison to those of cereals, buckwheat protein possesses high nutritional quality due to its high lysine and arginine levels and its well-balanced amino acids composition

* To whom correspondence should be addressed.

Phone: +421-2-59325 419; fax: +421-2-52967 085; e-mail: anna.mikulajova@stuba.sk

0139-3006/\$20.00 C 2015 Akadémiai Kiadó, Budapest 
(NiKolić et al., 2011). Wheat bran is a good source of dietary fibres and phenolic acids; the majority of the latter are insoluble and bound by ester and ether linkages to polysaccharides, such as arabinoxylan and lignin, in the cell wall (ZHANG et al., 2011).

Bread-making is a complex process involving significant physical and chemical changes. The level of bioactive compounds in grains can either decrease or increase during the process and their bioavailabilities may also be modified and the nutritional value of the final product altered (DEwETTINCK et al., 2008). In addition to the health benefits associated with cereal and pseudocereal antioxidants, these compounds may inhibit lipid oxidation in food and improve food quality and stability.

The aim of the present study was to supplement white wheat flour commonly used in bakeries with other cereals to obtain functional bakery products enriched with beneficial components. Based on preliminary studies, four types of cereal grains were included - whole buckwheat grain, whole barley grain, whole oat grain, and wheat bran. Wheat bran was chosen to study the possible use of this waste product from milling as a raw material for production of foods with beneficial nutritional properties. Total phenolic and flavonoid contents in the bakery products and their stability during technological process were evaluated. Antioxidant properties and their effectiveness in inhibiting lipid oxidation were also determined. Finally, the effects of supplementation on the sensory value of the final products were assessed.

\section{Materials and methods}

\subsection{Raw materials}

Commercial white wheat flour T 512 (Pohronský Ruskov mill, Slovak Republic) and tested cereals: whole buckwheat flour (Fagopyrum esculentum Moench, var. Špačinská), whole barley flour (Hordeum vulgare L., var. Virac), wheat bran flour (Triticum aestivum L., var. Kris), and whole oat flour (Avena sativa L., var. Zvolen) were provided by the Gene Bank of the Research Institute of Plant Production, Piešt'any, Slovak Republic.

\subsection{Baking experiments}

Composition of the round roll was: flour (300 g), baker's yeast (12.1 g), sunflower oil (7.5 g), salt (5.6 g), sugar (3.2 g), and water. The amount of water added was optimised using a Farinograph, according to the water absorption capacity of flour up to 350 farinograph unit. Procedure: ingredients were homogenised in a Farinograph mixer for $3 \mathrm{~min}$. The covered dough was left for $20 \mathrm{~min}$ at $30^{\circ} \mathrm{C}$, divided into smaller portions (weight $100 \mathrm{~g}$ ), and shaped into loaves in an Extensograph. The mixture was left to ferment for $45 \mathrm{~min}$ at $30{ }^{\circ} \mathrm{C}$ and baked in the electric oven for $13 \mathrm{~min}$ at $220^{\circ} \mathrm{C}$. The loaves were cooled to room temperature for $2 \mathrm{~h}$ and analysed sensorically and chemically. The control round roll sample contained only white wheat flour. In the experimental samples, $20 \%$ white wheat flour was substituted with tested cereals.

\subsection{Preparation of ethanol extracts}

Prior to extraction, samples were dried, milled, and ground to pass through a $0.75 \mathrm{~mm}$ sieve. Moisture content was determined using the ISO (2009) method and all data were expressed on a dry weight (DW) basis. The milled samples $(3 \mathrm{~g})$ were extracted at $80{ }^{\circ} \mathrm{C}$ for one $\mathrm{h}$ with 
$65 \%$ ethanol (1:20, w/v, three times) (MiKulajoví et al., 2007). Extracts were filtered, supernatants collected, and, after ethanol evaporation, phenolic compounds were extracted with ethyl acetate $(1: 1$, twice), concentrated to dryness, and dissolved in $96 \%$ ethanol. These extracts were used for determination of antioxidant activity by 2,2-diphenyl-1-picrylhydrazyl (DPPH) assay and for estimation of total phenolic and total flavonoid contents.

\subsection{Preparation of lipid extracts}

Lipids were obtained from finely ground baked products $(100 \mathrm{~g})$ by extraction with petroleum ether $(1: 3, \mathrm{w} / \mathrm{v})$ at room temperature for $3 \mathrm{~h}$ with shaking. Peroxide values were determined in the isolated lipid samples, as an indicator of the primary lipid oxidation products generated.

\subsection{Antioxidant activity determined by DPPH assay (AOA)}

The stable DPPH radical (Sigma-Aldrich, Steinheim, Germany) was used to measure the free radical scavenging capacity of the samples as described by Yen and CHEN (1995). The difference in absorbance at $517 \mathrm{~nm}$ relative to the reference spectrum was used to calculate total antioxidant capacity as the amount of scavenged DPPH radicals per gram of product dry weight (mg DPPH/g DW).

\subsection{Antioxidant activity determined by Peroxide value assay}

The peroxide value of the isolated lipid phase was measured according to A.O.A.C (1990). Primary oxidation products were expressed as meq. peroxide $/ \mathrm{kg}$ of fat.

\subsection{Total phenolic content (TPC)}

The TPC of ethanolic extracts were measured using the Folin-Ciocalteu assay as described by Yu and co-workers (2004). The TPC was determined using a standard curve of gallic acid (Sigma-Aldrich, Steinheim, Germany). The results were expressed in gallic acid equivalent per gram of product dry weight (mg GAE/g DW).

\subsection{Total flavonoid content (TFC)}

The TFC of ethanolic extracts was determined using the method of KREFT and co-workers (2002). The TFC was determined using a standard curve prepared for rutin (Sigma-Aldrich, Steinheim, Germany) and expressed in rutin equivalent per gram of product dry weight (mg rutin/g DW).

\subsection{Sensory evaluation}

The sensory evaluation of the final products was carried out by a panel of 11 assessors who had passed certificated and accredited sensory food examinations. The bakery products were evaluated for the following sensory attributes: shape, crust colour, crumb colour, elasticity and porosity, adhesive power to the palate during longer chewing, odour, taste, and overall acceptance. The technique of unstructured continuous line scale was used with the left side of scale corresponding to the lowest intensity and the right side corresponding to the highest intensity of the tested parameter and the hedonic scale technique was used with the highest degree corresponding to typical quality and the lowest degree (zero point) corresponding to 
the essential qualitative deficiencies. For neutralisation of the taste organ, panellists were required to rinse their mouth with clean water.

\subsection{Statistical analysis}

All analyses were run in quadruplet. The data obtained were reported as mean \pm standard deviation (SD). Results were subjected to correlation analysis (Pearson's correlation coefficient), one-way analysis of variance (ANOVA), and multiple range test - Fisher's least significant differences (LSD) at level of $\mathrm{P}=0.05$. Principal component analysis (PCA) was performed to obtain an overview of the sensory data. Statgraphic Plus, Version 3.1 (Statsoft; Tulsa, Oklahoma, USA) statistical analysis software was used.

\section{Results and discussion}

\subsection{Stability assessments of phenolic compounds}

The round roll with whole buckwheat flour was prepared and tested for AOA, TPC, and TFC at particular stages of the technological process and in the separate parts of the final product. The results are presented in Table 1, which shows that these parameters changed in the process of making round roll.

During baking, a number of different compounds are formed, for example, Maillard reaction products that are reported to possess antioxidant properties (metal chelation or inhibition of oxidation) and are localized mainly in the crust, where nonenzymatic browning reactions are favoured and can affect TPC estimation (PoKORNÝ et al., 2004; HoLTEKJøLEN et al., 2008). This can explain the highest AOA, as well as the TPC, found in buckwheat round roll crust in our study. In order to eliminate the contribution of such process-induced products, only round roll crumb was tested in subsequent experiments.

In the subsequent experiment, round rolls made with whole barley, whole oat, and wheat bran flours were tested. The stability of phenolic compounds and antioxidant behaviour are shown in Table 1. In all cases, the content of phenols in crumb was lower than in the respective flour mixtures and doughs. The losses during dough development and baking were moderate (ranging from $0.9 \%$ to $1.9 \%$ and $1.8 \%$ to $4.9 \%$ compared to flour, respectively), but these differences were statistically significant $(\mathrm{P}<0.05)$. Losses of flavonoids occurred during baking, however, rather than during dough-making. In contrast to flour, losses in baked buckwheat and barley crumb were 4.7 and 3.4\%, respectively. A decline in the AOA of the final products was also observed. In dough preparation, only small decreases were noted $(1.8-3.0 \%)$, whilst in the subsequent thermal process of baking the decrease was more marked $(8.8 \%-18.6 \%)$. The lowest decreases were found for buckwheat and barley flour, whereas the greatest decrease occurred in the control round roll.

The decrease of phenolic content and antioxidant activities during bread-making has been reported by several research teams (BOSKOv HANSEN et al., 2002; VogrinčIČ et al., 2010; SAKAČ et al., 2011). However, the magnitude of the changes varies according to the cereal material tested, the bread formulations, the temperature or time of heating, as well as depending on the extraction and analytical methods. However, some studies have reported a slightly increased level of total phenolics (GÉLInAs \& McKinnon, 2006; HolteKJølen et al., 2008). This can be explained, as the whole bakery products, containing the Maillard productenriched crust, were evaluated. 
Table 1. Total phenolic content (TPC, mg GAE/g DW), total flavonoid content (TFC, mg rutin/g DW) and antioxidant activity (AOA, mg DPPH/g DW) during round rolls processing

\begin{tabular}{|c|c|c|c|}
\hline & $\begin{array}{c}\text { TPC } \\
\text { (mg GAE/g DW) }\end{array}$ & $\begin{array}{c}\text { TFC } \\
\text { (mg rutin/g DW) }\end{array}$ & $\begin{array}{c}\mathrm{AOA} \\
(\mathrm{mg} \mathrm{DPPH} / \mathrm{g} \mathrm{DW})\end{array}$ \\
\hline \multicolumn{4}{|l|}{ Flours } \\
\hline White wheat & $0.31 \pm 0.001^{\mathrm{a}}$ & $0.01 \pm 0.0003^{\mathrm{a}}$ & $0.13 \pm 0.002^{\mathrm{a}}$ \\
\hline Wheat/buckwheat & $0.76 \pm 0.002^{b}$ & $0.13 \pm 0.002^{b}$ & $1.76 \pm 0.01^{\mathrm{b}}$ \\
\hline Wheat/barley & $0.53 \pm 0.004^{\mathrm{c}}$ & $0.11 \pm 0.001^{\mathrm{c}}$ & $0.96 \pm 0.01^{\mathrm{c}}$ \\
\hline Wheat/oat & $0.45 \pm 0.002^{\mathrm{d}}$ & $0.02 \pm 0.001^{\mathrm{d}}$ & $0.36 \pm 0.002^{\mathrm{d}}$ \\
\hline Wheat/wheat bran & $0.46 \pm 0.002^{\mathrm{e}}$ & $0.03 \pm 0.001^{\mathrm{e}}$ & $0.59 \pm 0.002^{\mathrm{e}}$ \\
\hline \multicolumn{4}{|l|}{ Doughs } \\
\hline White wheat & $0.32 \pm 0.003^{\mathrm{f}}$ & $0.01 \pm 0.001^{\mathrm{f}}$ & $0.13 \pm 0.001^{\mathrm{f}}$ \\
\hline Wheat/buckwheat & $0.77 \pm 0.003^{\mathrm{g}}$ & $0.13 \pm 0.002^{\mathrm{b}}$ & $1.73 \pm 0.01^{\mathrm{g}}$ \\
\hline Wheat/barley & $0.52 \pm 0.01^{\mathrm{h}}$ & $0.11 \pm 0.001^{\mathrm{g}}$ & $0.94 \pm 0.02^{\mathrm{h}}$ \\
\hline Wheat/oat & $0.44 \pm 0.004^{\mathrm{i}}$ & $0.02 \pm 0.001^{\mathrm{h}}$ & $0.35 \pm 0.003^{\mathrm{i}}$ \\
\hline Wheat/wheat bran & $0.46 \pm 0.002^{\mathrm{j}}$ & $0.03 \pm 0.001^{\mathrm{i}}$ & $0.58 \pm 0.01^{\mathrm{j}}$ \\
\hline \multicolumn{4}{|l|}{ Round roll crumbs } \\
\hline White wheat & $0.31 \pm 0.004^{\mathrm{k}}$ & $0.01 \pm 0.001^{\mathrm{j}}$ & $0.11 \pm 0.015^{\mathrm{k}}$ \\
\hline \multicolumn{4}{|l|}{ Wheat/buckwheat } \\
\hline Crumb & $0.75 \pm 0.002^{1, \mathrm{~A}}$ & $0.12 \pm 0.001^{\mathrm{k}, \mathrm{A}}$ & $1.58 \pm 0.02^{1, \mathrm{~A}}$ \\
\hline Crust & $0.92 \pm 0.03^{\mathrm{B}}$ & $0.16 \pm 0.001^{\mathrm{B}}$ & $1.92 \pm 0.04^{\mathrm{B}}$ \\
\hline Whole round roll & $0.75 \pm 0.004^{\mathrm{C}}$ & $0.14 \pm 0.001^{\mathrm{C}}$ & $1.68 \pm 0.035^{\mathrm{C}}$ \\
\hline Wheat/barley & $0.51 \pm 0.01^{\mathrm{m}}$ & $0.10 \pm 0.001^{1}$ & $0.85 \pm 0.01^{\mathrm{m}}$ \\
\hline Wheat/oat & $0.42 \pm 0.01^{\mathrm{n}}$ & $0.029 \pm 0.001^{\mathrm{d}}$ & $0.31 \pm 0.01^{\mathrm{n}}$ \\
\hline Wheat/wheat bran & $0.44 \pm 0.002^{\circ}$ & $0.03 \pm 0.001^{\mathrm{e}}$ & $0.51 \pm 0.01^{\circ}$ \\
\hline
\end{tabular}

Each value is expressed as mean \pm standard deviation $(S D, n=4)$.

a-o, A-C Values in column followed by different letters are significantly different $(\mathrm{P}<0.05)$

It can be concluded that to improve the functional properties of these bakery products, their formulas and preparation conditions must be optimised. 


\subsection{Evaluation of the improved round roll properties}

Assessment of the effects of whole cereal grain supplementation of white wheat on phenolic amounts and AOA is presented in Table 1.

The TPC of all enhanced round rolls were markedly higher than that in the control round rolls $(\mathrm{P}<0.05)$. The highest value was found for buckwheat-supplemented wheat round rolls. The TPC was, in descending order: buckwheat round roll (about $58.9 \%$ of that in the control rolls) $>$ barley round roll (about 39.6\%) > wheat bran round roll (about 30.5\%) $>$ oat round roll (about 27.6\%). Addition of other whole cereal grains, especially buckwheat and barley, into white wheat round rolls greatly enhanced their TFC (12-fold and 10-fold, respectively). Such addition also led to significant increases in the AOA of the final rolls $(\mathrm{P}<0.05)$. The highest overall value was found when buckwheat was added. AOA decreased in the order: buckwheat round roll $(93.3 \%$ of that in the control rolls $)>$ barley round roll $(87.6 \%)>$ wheat bran round roll $(79.5 \%)>$ oat round roll $(65.9 \%)$.

In this study, a significant correlation $(\mathrm{R}=0.99)$ was found between the AOA and the TPC of the round rolls, which suggests that most of the antioxidant effects were due to the presence of phenolics. The results showed that both the quantity and quality of the polyphenols are factors affecting antioxidant behaviour. It can also be concluded that flavonoids such as quercetin, catechins, rutin, and procyanidins are mainly responsible for antioxidant properties of buckwheat and barley. These compounds are better antioxidants than ferulic acid, the main phenolic compound in wheat bran and oat grain. This study showed that the supplementation of cereal bran or whole cereal grain resulted in improved antioxidant properties, since bran contains more antioxidants than grain endosperm. Replacement of the white wheat flour traditionally used by tested cereals enhanced both the TPC and AOA. These findings have favourable technological and health implications.

\subsection{Oxidation stability of lipids}

During processing and storage of bakery products lipid oxidation occurs. Compounds possessing antioxidant properties play a crucial role in preventing lipid oxidation in food during processing and storage, thereby maintaining shelf life and consumer acceptability. Because of this, the peroxide value was measured as marker of lipid hydroperoxide production. These data are illustrated in Figure 1. The peroxide value of white wheat round roll (137.16 meq. peroxide $/ \mathrm{kg}$ of fat) was the highest of all the evaluated products. Enhancing white wheat flour with other cereals has a high positive impact on lipid stabilisation during the subsequent heat treatments. The percentage inhibition of lipid oxidation exceeded $50 \%$. The lowest amount of hydroperoxides was detected in round roll made with barley flour and the effectiveness of lipid protection was, in descending order, barley round roll $(69.4 \%$ increase $)>$ oat round roll $(57.1 \%)=$ buckwheat round roll $(57.1 \%)>$ wheat bran round roll $(54.7 \%)$.

There was a low correlation $(\mathrm{R}=0.59)$ between TPC and the peroxide value of the final products. This demonstrates that other antioxidants beside phenolic compounds, as tocopherols, sterols, or carotenoids, play a significant role in the prevention of oxidation. 


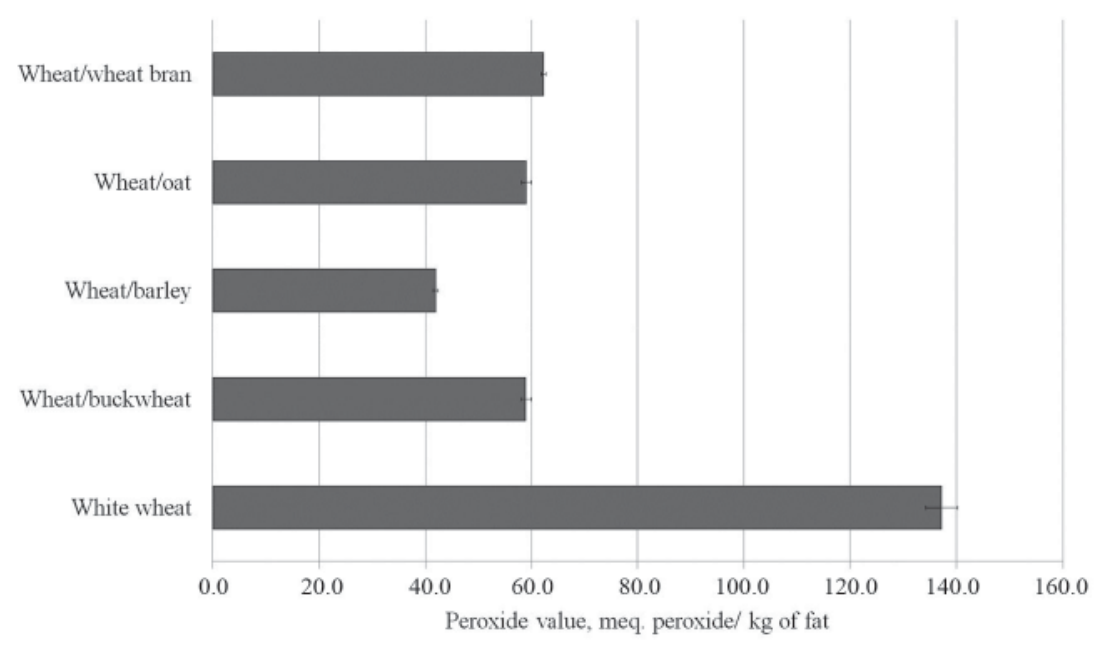

Fig. 1. The peroxide value (meq. peroxide $/ \mathrm{kg}$ of fat) of evaluated round rolls

\subsection{Sensory evaluation}

The panellists assessed both the external and internal attributes; the external characters are determinative from consumer's perspective. The best shape and crust colour was observed in the product supplemented with wheat bran. Product supplemented with barley and oat grain had flat shapes. The addition of whole buckwheat flour or, to a lesser extent, by wheat bran flour, had positive effects on crumb colour and crumb porosity. These two supplementations showed good crumb elasticity and adhesiveness to palate. The results of ANOVA showed significant differences to be found in the crust colour of white wheat round roll and round rolls with buckwheat and wheat bran, and in crumb elasticity for all the round rolls studied here. Moreover, significant differences were found in odour descriptors between white wheat round roll and oat round roll. It was also concluded that overall acceptance of round roll with barley and oat differed significantly from white wheat round rolls (Table 2).

Correlation analysis showed highly positive correlations between pleasantness of odour and typical odour $(\mathrm{R}=0.86)$, stale odour and burnt odour $(\mathrm{R}=0.86)$, overall acceptance and pleasantness of taste $(\mathrm{R}=0.86)$, pleasantness of taste and typical taste $(\mathrm{R}=0.83)$. It was concluded that there is a direct linear dependence between these variables. Moreover, highly negative correlations were recorded between bitter taste and typical taste $(\mathrm{R}=-0.73)$ and between overall acceptance and bitter taste $(\mathrm{R}=-0.80)$, indicating a high indirect linear dependence between these variables. The small values of correlation coefficients between other variables denoted that the relationship between these was not linear.

PCA indicated the existence of 3 principal components - dimensions ( $\mathrm{PC} 1, \mathrm{PC} 2$, and PC3) for 13 sensory attributes (sensory parameters); together these explain $77.15 \%$ of the variation, with PC1 explaining 48.94\%, PC2 20.14\%, and PC3 8.07\%. The loadings plot of these 3 principal components showed that the attributes explain the main variation of the bakery products in this study. PC1 was strongly associated with variables such as overall acceptance, pleasantness of odour and taste, and typical odour and taste, PC2 negatively correlated with burnt and stale odour, and PC3 was related most closely to crust colour (Fig. 2). 
Table 2. Results of selected sensory parameters of studied round roll (\%)

\begin{tabular}{|c|c|c|c|c|c|}
\hline & White wheat & $\begin{array}{c}\text { Wheat/ } \\
\text { buckwheat }\end{array}$ & $\begin{array}{l}\text { Wheat/ } \\
\text { barley }\end{array}$ & $\begin{array}{c}\text { Wheat/ } \\
\text { oat }\end{array}$ & $\begin{array}{c}\text { Wheat/ } \\
\text { wheat bran }\end{array}$ \\
\hline Crust colour & $81.0 \pm 5.8^{\mathrm{a}}$ & $92.09 \pm 4.8^{b}$ & $86.2 \pm 5.7^{\mathrm{a}}$ & $84.1 \pm 3.5^{\mathrm{a}}$ & $97.0 \pm 1.8^{\mathrm{c}}$ \\
\hline Crumb elasticity & $97.8 \pm 1.6^{\mathrm{a}}$ & $87.9 \pm 1.7^{b}$ & $74.6 \pm 1.4^{\mathrm{c}}$ & $40.7 \pm 1.2^{\mathrm{d}}$ & $85.8 \pm 5.7^{\mathrm{e}}$ \\
\hline \multicolumn{6}{|l|}{ Odour descriptors } \\
\hline Typical & $90.9 \pm 4.7^{\mathrm{a}}$ & $90.9 \pm 5.8^{\mathrm{a}}$ & $88.0 \pm 4.2^{\mathrm{a}}$ & $68.8 \pm 2.2^{\mathrm{b}}$ & $91.1 \pm 3.7^{\mathrm{a}}$ \\
\hline Foreign & $0.7 \pm 0.0^{\mathrm{a}}$ & $3.6 \pm 0.2^{\mathrm{a}}$ & $3.3 \pm 0.1^{\mathrm{a}}$ & $8.9 \pm 0.3^{b}$ & $1.4 \pm 0.1^{\mathrm{a}}$ \\
\hline Burnt & $1.7 \pm 0.0^{\mathrm{a}}$ & $3.0 \pm 0.1^{\mathrm{a}}$ & $3.0 \pm 0.1^{\mathrm{a}}$ & $2.2 \pm 0.1^{\mathrm{a}}$ & $1.7 \pm 0.0^{\mathrm{a}}$ \\
\hline Stale & $1.3 \pm 0.0^{\mathrm{a}}$ & $2.9 \pm 0.1^{\mathrm{a}}$ & $0.7 \pm 0.0^{\mathrm{a}}$ & $3.0 \pm 0.2^{\mathrm{a}}$ & $0.6 \pm 0.0^{\mathrm{a}}$ \\
\hline Pleasantness of odour & $80.5 \pm 1.5^{\mathrm{a}}$ & $93.8 \pm 1.4^{\mathrm{a}}$ & $80.2 \pm 4.9^{\mathrm{a}}$ & $60.6 \pm 2.1^{b}$ & $90.0 \pm 4.0^{\mathrm{a}}$ \\
\hline \multicolumn{6}{|l|}{ Taste descriptors } \\
\hline Typical & $92.4 \pm 5.4^{\mathrm{a}}$ & $85.3 \pm 4.9^{\mathrm{a}}$ & $81.7 \pm 1.3^{\mathrm{b}}$ & $62.1 \pm 2.3^{\mathrm{c}}$ & $88.1 \pm 5.3^{\mathrm{a}}$ \\
\hline Herbal & $1.1 \pm 0.0^{\mathrm{a}}$ & $6.8 \pm 0.1^{\mathrm{b}}$ & $2.6 \pm 0.1^{\mathrm{a}}$ & $9.8 \pm 0.5^{\mathrm{c}}$ & $4.18 \pm 0.2^{\mathrm{a}}$ \\
\hline Bitter & $1.2 \pm 0.0^{\mathrm{a}}$ & $3.6 \pm 0.0^{\mathrm{a}}$ & $3.2 \pm 0.1^{\mathrm{a}}$ & $34.6 \pm 2.6^{\mathrm{b}}$ & $5.2 \pm 0.1^{\mathrm{a}}$ \\
\hline Empty & $3.9 \pm 0.1^{\mathrm{a}}$ & $1.3 \pm 0.0^{\mathrm{a}}$ & $4.0 \pm 0.2^{\mathrm{a}}$ & $6.3 \pm 0.2^{\mathrm{a}}$ & $2.3 \pm 0.1^{\mathrm{a}}$ \\
\hline Pleasantness of taste & $88.7 \pm 6.5^{\mathrm{a}}$ & $75.8 \pm 2.1^{\mathrm{a}}$ & $72.5 \pm 1.8^{b}$ & $42.2 \pm 0.2^{\mathrm{c}}$ & $87.5 \pm 4.1^{\mathrm{a}}$ \\
\hline Overall acceptance & $88.3 \pm 7.8^{\mathrm{a}}$ & $88.9 \pm 2.9^{\mathrm{a}}$ & $73.2 \pm 1.4^{\mathrm{b}}$ & $40.5 \pm 1.9^{c}$ & $89.3 \pm 6.3^{\mathrm{a}}$ \\
\hline
\end{tabular}

Each value is expressed as mean \pm standard deviation $(\mathrm{SD}, \mathrm{n}=11)$.

${ }^{\mathrm{a}-\mathrm{e}}$ Values in row followed by different letters are significantly different $(\mathrm{P}<0.05$, ANOVA and LSD test)

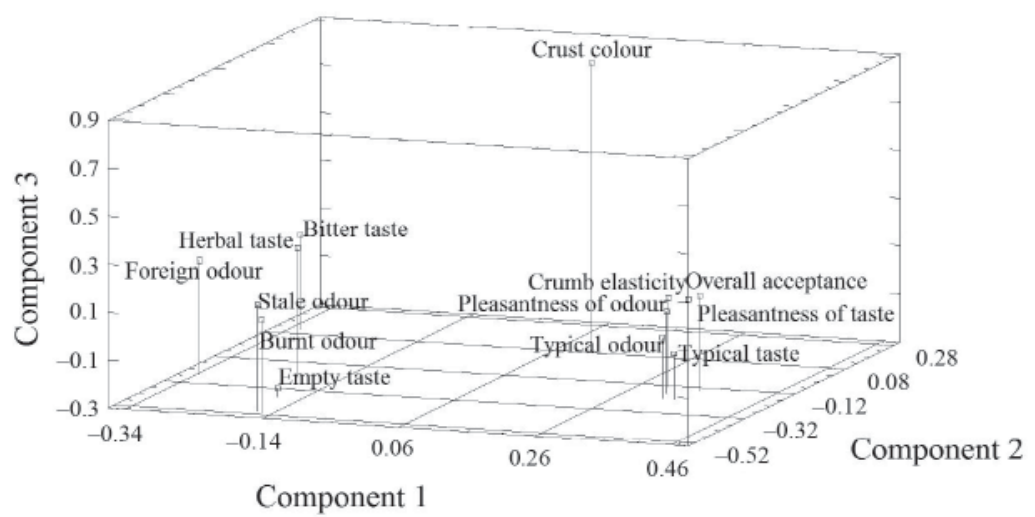

Fig. 2. Loadings plot for the first three principal components obtained by PCA for sensory parameters of round rolls 
Sensory analyses indicate that most of the evaluated sensory characteristics were positively affected by wheat bran and buckwheat flour supplementation, in contrast to that of oat flour, which had a negative effect on product shape, porosity, elasticity, and adhesiveness of crumb, taste and overall acceptability.

\section{Conclusions}

These results suggest that partial substitution of traditionally-used white wheat flour by other cereals in white round rolls improves antioxidant effects and phenolic contents. Supplementation with buckwheat flour produced a 15-fold increase in AOA, a 2-fold increase of TPC, and a 12-fold increase of TFC in round roll crumbs. The retention of phenolic compounds, especially flavonoids, during food processing, through optimisation of recipe ingredients and baking conditions, deserves more attention because of its effect in lipid oxidation, not only in food, but also in cell membranes, where phenolics act as effective antioxidants. The results of sensory profiling suggest that a $20 \%$ substitution with all the tested cereal flours in bakery product formula could be appropriate for product acceptability, except in the case of oat flour, where lower levels should be added.

The work was supported by The Agency of the Ministry of Education, Science, Research and Sport of the Slovak Republic for the Structural Funds of EU (ITMS 26240220040), the Slovak Research and Development Agency (VMSP-II-0024-09) and by Slovak Grant Agency for Science VEGA (1/0453/13).

\section{References}

A.O.A.C (1990): Official methods of analysis food composition; additives; natural contaminants. Association of Official Analytical Chemists, Virginia, Method no. 965.33.

Boskov Hansen, H., Andreasen, M., Nielsen, M., Larsen, L., Knudsen, B.K., Meyer, A., Christensen, L. \& Hansen, Å. (2002): Changes in dietary fibre, phenolic acids and activity of endogenous enzymes during rye breadmaking. Eur. Food Res. Technol., 214, 33-42.

Dewettinck, K., Van Bockstaele, F., Kuhne, B., Van de Walle, D., Courtens, T.M. \& Gellynck, X. (2008): Nutritional value of bread: Influence of processing, food interaction and consumer perception. J. Cereal Sci., 48, 243-257.

GÉlinas, P. \& McKinnon, C.M. (2006): Effect of wheat variety, farming site, and bread-baking on total phenolics. Int. J. Food Sci. Technol., 41, 329-332.

Holtekjølen, A.K., Bævre, A.B., Rødbotten, M., Berg, H. \& Knutsen, S.H. (2008): Antioxidant properties and sensory profiles of breads containing barley flour. Food Chem., 110, 414-421.

ISO (2009): Cereals and cereal products - Determination of moisture content - Reference method. No. 712:2009

IZYDORCZyK, M.S. \& DeXTER, J.E. (2008): Barley $\beta$-glucans and arabinoxylans: Molecular structure, physicochemical properties, and uses in food products - a review. Food Res. Int., 41, 850-868.

Kreft, S., ŠtrukelJ, B., GaberščiK, A. \& Kreft, I. (2002): Rutin in buckwheat herbs grown at different UV-B radiation levels: comparison of two UV spectrophotometric and an HPLC method. J. Exp. Bot., 53, 18011804.

MikulajovÁ, A., TakácsovÁ, M., Alexy, P. \& BrindzovÁ, L. (2007): Optimalizacia extrakcie fenolovŷch zložiek z pohŷnky na základe vŷsledkov plánovaného experimentu. (Optimalization of extraction of phenolic compounds from buckwheat on the basis of results of experimental design method). Chem. Listy, 101, 563568.

Miller, H.E., Rigelhof, F., Marquart, L., Prakash, A. \& Kanter, M. (2000): Antioxidant content of whole grain breakfast cereals, fruits and vegetables. J. Am. Coll. Nutr., 19, 312-319.

Acta Alimentaria 44, 2015 
Nikolić, N., SaKaČ, M. \& Mastilović, J. (2011): Effect of buckwheat flour addition to wheat flour on acylglycerols and fatty acids composition and rheology properties. Food Sci. Technol., 44, 650-655.

Pokorný, J., Schmidt, Š. \& Nguyen, H.T.T. (2004): Functionality changes of natural antioxidants during food processing and storage. Czech J. Food Sci., 22, 80-83.

Sakač, M., Torbica, A., Sedej, I. \& Hadnaøev, M. (2011): Influence of breadmaking on antioxidant capacity of gluten free breads based on rice and buckwheat flours. Food Res. Int., 44, 2806-2813.

Tiwari, U. \& Cummins, E. (2012): Dietary exposure assessment of $\beta$-glucan in a barley and oat based bread. LWT Food Sci. Technol., 47, 413-420.

Vogrinčič, M., Timoracká, M., Melicháčová, S., Vollmannová, A. \& Kreft, I. (2010): Degradation of rutin and polyphenols during the preparation of tartary buckwheat bread. J. Agr. Food Chem., 58, 4883-4887.

Yen, G.CH. \& Chen, H.Y. (1995): Antioxidant activity of various tea extracts in relation to their mutagenicity. J. Agr. Food Chem., 43, 27-32.

Yu, L., Haley, S., Perret, J. \& Harris, M. (2004): Comparison of wheat flours grown at different locations for their antioxidant properties. Food Chem., 86, 11-16.

Zhang, Y., Pitkänen, L., Douglade, J., Tenkanen, M., Remond, C. \& Joly, C. (2011): Wheat bran arabinoxylans: Chemical structure and film properties of three isolated fractions. Carbohyd. Polym., 86, 852-859. 